\title{
A Child with Prostaglandin I2-associated Thyrotoxicosis: Case Report
}

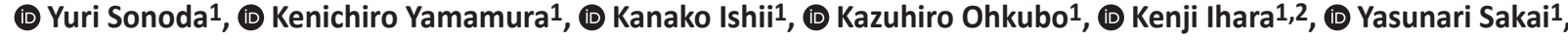 \\ (D) Shouichi Ohga1 \\ ${ }^{1}$ Kyushu University Graduate School of Medical Sciences, Department of Pediatrics, Fukuoka, Japan \\ 2Oita University Faculty of Medicine, Department of Pediatrics, Oita, Japan
}

\begin{abstract}
What is already known on this topic?
Continuous intravenous injection of epoprostenol prostaglandin $\mathrm{I}_{2}\left(\mathrm{PGI}_{2}\right)$ is an effective medication for patients with severe cardiac failure due to pulmonary artery hypertension. $\mathrm{PGI}_{2}$ may cause the life-threatening side effect of hyperthyroidism with an incidence rate of $6.7 \%$.
\end{abstract}

\section{What this study adds?}

We report the first pediatric case with portosystemic venous shunt syndrome, a patient who developed thyrotoxicosis after 10 years of prostaglandin $\mathrm{I}_{2}\left(\mathrm{PGI}_{2}\right)$ treatment. Prophylactic monitoring of thyroid function is mandatory for pediatric pulmonary artery hypertension patients undergoing $\mathrm{PGI}_{2}$ treatment.

\begin{abstract}
Prostaglandin $\mathrm{I}_{2}\left(\mathrm{PGI}_{2}\right)$ causes hyperthyroidism, a critical complication in patients with pulmonary arterial hypertension (PAH). However, it remains unknown whether $\mathrm{PGI}_{2}$ may have unfavorable effects on thyroid function in children with congenital portosystemic venous shunt syndrome (CPSVS). We present a boy with CPSVS who developed PAH at seven years of age. During ongoing PGI 2 therapy, he experienced thyrotoxicosis at 17 years of age. The literature review showed that the reported 12 patients with PAH (median 11 years of age) developed hyperthyroidism during between one and 11 years of $\mathrm{PGI}_{2}$ treatment. Only one patient survived the acute PAH crisis due to hyperthyroidism. These data provide evidence that prophylactic intervention for hyperthyroidism is indicated for children with CPSVS during $\mathrm{PGI}_{2}$ treatment.

Keywords: Prostaglandin $\mathrm{I}_{2}$, pulmonary arterial hypertension, congenital portosystemic venous shunt syndrome, hyperthyroidism
\end{abstract}

\section{Introduction}

Pulmonary arterial hypertension $(\mathrm{PAH})$ is a rare vascular disorder that has an annual incidence of 5 to 8 per million children under the age of 18 (1). With the advances in pharmacological management, the 5-year survival for $\mathrm{PAH}$ has risen to $60 \%$ over the past decades (2). Continuous intravenous injection of epoprostenol prostaglandin $\mathrm{I}_{2}\left(\mathrm{PGI}_{2}\right)$ has been used in patients with severe PAH (2). This medication has contributed to improving the prognosis of primary $\mathrm{PAH}$. However, $\mathrm{PGI}_{2}$ may cause a side effect of hyperthyroidism in $6.7 \%$ of the subjects (3). Thus, establishing the safest treatment strategies for PAH remains a challenge.
Here we report a 17-year-old boy with congenital portosystemic venous shunt syndrome (CPSVS), who developed severe hyperthyroidism during $\mathrm{PGI}_{2}$ treatment. We also describe the demographic features of previously reported cases with $\mathrm{PGI}_{2}$-associated hyperthyroidism by collecting their profiles from the literature.

\section{Case Report}

A 20-day-old male infant was referred to our hospital because of hypergalactosemia detected during neonatal mass screening test. He was diagnosed with congenital 
portal vein hypoplasia and CPSVS. At seven years of age, PAH was found on regular checkup using echocardiography. Continuous intravenous $\mathrm{PGI}_{2}(47.2 \mathrm{ng} / \mathrm{kg} / \mathrm{min})$ was initiated at nine years of age. The administration of bosentan hydrate $(62.5 \mathrm{mg} /$ day) was added at age 10 years. The treatment strategy for his cardiac status was based on World Health Organization (WHO) functional class 2 . The right ventricular systolic pressure, estimated from the moderate tricuspid regurgitation, was $80 \mathrm{mmHg}$ on echocardiography. He underwent an assessment of thyroid function once at 16 years of age. The test results showed a low thyroid stimulating hormone (TSH) of $0.04 \mu \mathrm{U} / \mathrm{mL}$, [reference range (rr): 0.27-4.20] and normal free T4 concentration of 1.42 ng/dL, (rr: 1.00-1.80).

At age 17 years, the patient was admitted to our hospital because of dyspnea, general fatigue and chest pain (WHO class 4). The body temperature was $37.5{ }^{\circ} \mathrm{C}$ and the heart rate was $120 \mathrm{bpm}$. On admission, his height was $162.4 \mathrm{~cm}$ [-1.1 standard deviation (SD)] and body weight was $44.1 \mathrm{~kg}(-1.8 \mathrm{SD})$ resulting in a body mass index of 16.4. Goiter was noted and the liver was palpable at 4.0 $\mathrm{cm}$ below the costal margin. Intensified pulmonic sounds with regurgitant systolic murmur was remarkable at the left sternal border. Cardiomegaly was evident on chest radiography. Echocardiography revealed severe tricuspid regurgitation with elevated right ventricular systolic pressure (120 mmHg). A unilateral enlargement of the thyroid gland was detected on ultrasonography with increased blood flow and the estimated thyroid weight was calculated as $3.1 \mathrm{~g}$ (right) and $16.7 \mathrm{~g}$ (left). Laboratory tests showed a C-reactive protein concentration of $1.8 \mathrm{mg} / \mathrm{dL}$. Brain-type natriuretic peptide was $601.1 \mathrm{pg} / \mathrm{mL}$ (cut-off $\leq 18.4$ ), TSH $<0.01 \mu \mathrm{IU} /$ $\mathrm{mL}$, free $\mathrm{T} 4$ at $6.35 \mathrm{ng} / \mathrm{dL}$ (rr: 1.00-1.80), thyroid stimulating antibody (TSAb) elevated to $2691 \%$ (rr: < $180 \%$ ), TSH receptor antibody (TRAb) level was $10.7 \mathrm{U} / \mathrm{L}(\mathrm{rr}:<1.0 \mathrm{U} / \mathrm{L})$ and thyroglobulin antibody level $1349.7 \mathrm{U} / \mathrm{mL}$ (rr: < $45 \mathrm{U} / \mathrm{L})$.

Maximum doses of oral thiamazole, potassium iodide and intravenous hydrocortisone treatment failed to control the raging storm of hyperthyroidism. High-dose methylprednisolone therapy and destructive radioiodine (RI) (RI in Table 1) therapy were concurrently initiated on the $88^{\text {th }}$ day of admission. Hyperthyroidism gradually improved after the combined therapy. $\mathrm{PGI}_{2}$ was continued throughout the period of intensive care because PAH had been severe. When PAH started to improve, the estimated right ventricular pressure declined to $70 \mathrm{mmHg}$. The patient was discharged 132 days after admission (Figure 1). PAH has been controlled with euthyroid status thereafter. The patient has not received antithyroid therapy for more than four years although TSAb, TRAb and anti-thyroglobulin

\begin{tabular}{|c|c|c|c|c|c|c|c|}
\hline Patient number & Sex & $\begin{array}{l}\text { Age at } \\
\text { diagnosis } \\
\text { of PAH } \\
\text { (years) }\end{array}$ & $\begin{array}{l}\text { Age at } \\
\text { diagnosis } \\
\text { of }\end{array}$ & $\begin{array}{l}\text { PAH severity } \\
\text { (WHO } \\
\text { functional class) } \\
\text { at diagnosis of } \\
\text { hyperthyroidism }\end{array}$ & $\begin{array}{l}\text { Treatment of } \\
\text { hyperthyroidism }\end{array}$ & Outcome & Reference \\
\hline 1 & $\mathrm{~F}$ & 4 & 12 & ND & MMI & Alive & Satoh et al (4) \\
\hline 3 & $\mathrm{~F}$ & 11 & 15 & ND & MMI & Alive & Satoh et al (4) \\
\hline 4 & M & 11 & 19 & ND & Observation & Alive & Satoh et al (4) \\
\hline 5 & $\mathrm{~F}$ & 2 & 6 & 2 & MMI & Alive & Trapp et al (5) \\
\hline 6 & $\mathrm{~F}$ & 4 & 9 & 2 & MMI & Alive & Trapp et al (5) \\
\hline 7 & $\mathrm{~F}$ & 6 & 11 & 2 & MMI & Alive & Trapp et al (5) \\
\hline 11 & $\mathrm{~F}$ & 16 & 17 & 4 & PTU/MMI, SSKI, CS & Dead & Trapp et al (5) \\
\hline 12 & $\mathrm{~F}$ & 17 & 19 & 4 & $\begin{array}{l}\text { PTU/MMI, SSKI, CS, } \\
\text { esmolol, thyroidectomy }\end{array}$ & Alive & Trapp et al (5) \\
\hline 13 & M & 7 & 17 & 4 & MMI, SSKI, CS, RI & Alive & The present case \\
\hline Mean & & 9.2 & 14.7 & & & & \\
\hline Median (range) & & $11(2-17)$ & $15.8(6-19)$ & & & & \\
\hline
\end{tabular}




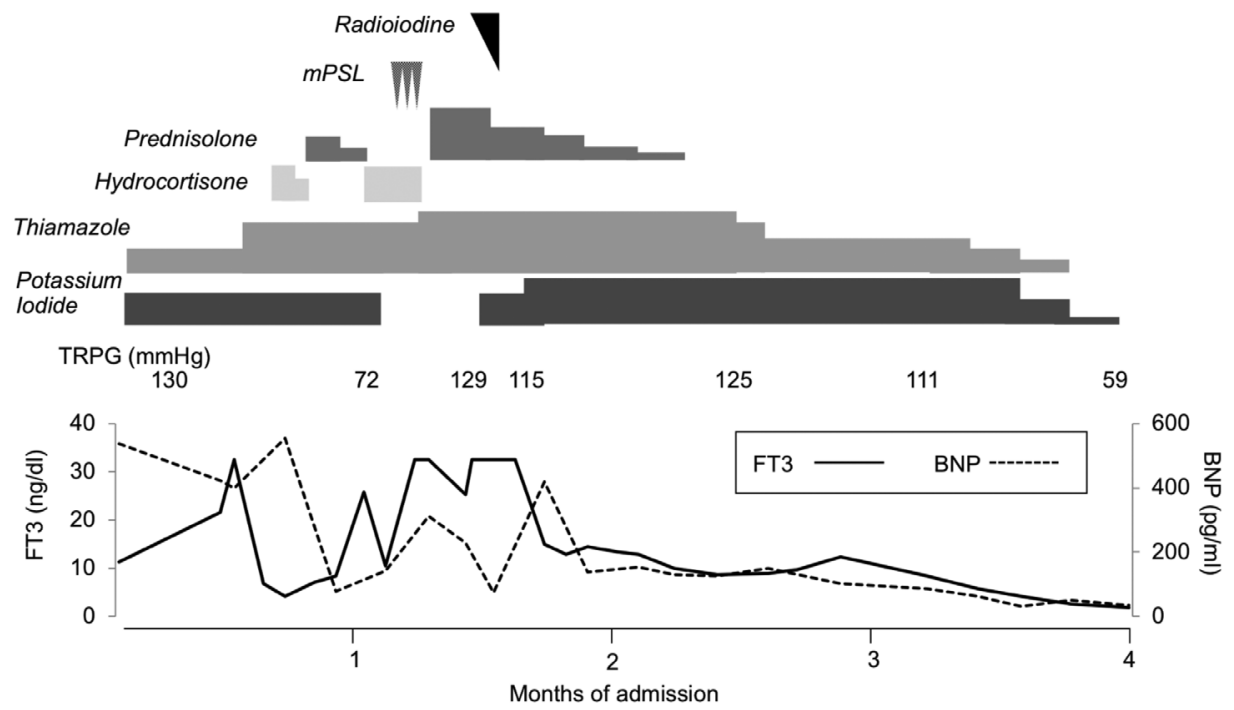

Figure 1. Treatment course of the present case after admission. Applied medications (italics) and their duration of treatment (blocks) are shown at the top. Radioiodine (410 MBq), methylprednisolone (1 g/day for three days), prednisolone (10-45 mg/ $\mathrm{kg} /$ day), oral administration of thiamazole (15-75 mg/day) and potassium iodide (200-300 mg/day) were used to control the thyrotoxicosis. Echocardiography-based measurements of tricuspid regurgitation peak gradient are shown in the middle. Line charts at the bottom indicate the declining concentrations of free-T3 (reference range: $2.2-4.4 \mathrm{pg} / \mathrm{mL}$ ) and brain natriuretic peptide (reference range: $\leq 18.4 \mathrm{pg} / \mathrm{mL}$ ) over four months of intensive care for the present case

MPSL: methylprednisolone, PSL: prednisolone, TRPG: tricuspid regurgitation peak gradient, FT3: free-T3, BNP: brain natriuretic peptide

antibody levels continue to be abnormal. None of his family members were affected by autoimmune thyroiditis. He had no past history of other autoimmune disorders. He had never experienced hypoglycemia, hyperandrogenism or other metabolic attacks before and after this episode.

Written informed consent was obtained from the patient and his parents for the publication of this report.

\section{Literature Review}

We performed a literature search for patients under the age of 20 years who presented with hyperthyroidism during treatment with $\mathrm{PGI}_{2}$. We found that 12 such cases had been reported in the years from 2010 to 2017 (4,5). Table 1 summarizes the clinical profiles of these 12 cases and compares with data from our patient (case 13 in Table 1). The median (range) age at diagnosis of PAH was 11 (2-17) years, while the hyperthyroidism developed at a median (range) age of 15.8 (6-19) years. Thus, duration to the development of $\mathrm{PGI}_{2}$-associated thyroiditis varied widely from 1 to 11 years after the diagnosis of PAH. Four patients (31\%) died of complications including cardiopulmonary dysfunction. We found that six (cases 8-13) among the 13 cases had severe cardiac dysfunction (WHO class 4). Although these six patients underwent thyroidectomy, propylthiouracil or RI therapies, only two (case 12 and the present case) survived the critical period.

\section{Discussion}

We described a case with exacerbated $\mathrm{PAH}$ during $\mathrm{PGI}_{2}$ treatment. The literature review for the reported cases under 20 years of age indicated a high mortality rate $(31 \%)$ for PAH patients when complicated by hyperthyroidism. Unfavorable prognosis of PAH was likely to be associated with the severity of cardiac dysfunction at the onset of hyperthyroidism.

$\mathrm{PGI}_{2}$ regulates both innate and adaptive immune responses. Recent studies showed evidence that it accelerates the differentiation of naïve $\mathrm{T}$ cells into Th1 7 cells and enhances Th1 7 cell functions $(4,6,7,8)$. The Th17-interleukin (IL)-17 axis may thus explain the mechanisms of $\mathrm{PGI}_{2}$-associated hyperthyroidism and thyroiditis. Considering that the earlier 12 cases presented with hyperthyroidism years after the diagnosis of PAH, the pathogenic mechanisms were less likely to involve acute reactions to $\mathrm{PGI}_{2}$. We speculate that deregulation of the physiological immune system by persistent exposure to $\mathrm{PGI}_{2}$ in $\mathrm{PAH}$ patients might be one of the causes augmenting the pathogenesis of hyperthyroidism. Although we have not analyzed the population of Th17 cells or IL-17 in peripheral blood in our patient, serial immunological studies may detect the prodromal signs of hyperthyroidism in PAH patients. 
Experimental studies demonstrated that $\mathrm{PGI}_{2}$ regulates both innate and adaptive immune systems (9). $\mathrm{PGI}_{2}$ analogs were also shown to inhibit proinflammatory responses to lipopolysaccharides in monocyte and macrophage populations (10). Notably, inflammatory macrophage populations were reported to be expanded in the lungs a mouse model of PAH (11). Thus, delineating the downstream signals to $\mathrm{PGI}_{2}$ in the lung macrophage will be the key to understand its deleterious effects on thyroid functions. Among them, monocyte chemoattractant protein-1 (MCP1/CCL2) is known as a downstream molecule following prostaglandin stimulation (12). Paradoxical effects of $\mathrm{PGI}_{2}$ on thyroid functions might therefore result from differential MCP-1 synthesis in each tissue as a result of long-term treatments.

We considered that the exacerbation of PAH was a consequence not only of the increased cardiac outputs with hyperthyroidism, but also from the direct effect of thyroid hormone on proliferative vascular endothelial cells (13). Together with our case report, the literature review also supports the necessity of prophylactic monitoring and management of thyroid function for PAH patients undergoing $\mathrm{PGI}_{2}$ treatment. Earlier intervention may prevent $\mathrm{PAH}$ patients from the progressive worsening of cardiac dysfunction. In this regard, prophylactic therapy might have been helpful if initiated in our patient at age 16 years, when he showed a low TSH concentration on thyroid testing. Future studies will clarify whether this alternative strategy might have changed the unfavorable outcomes of these patients.

\section{Acknowledgements}

We thank Dr. Toshiro Hara at Fukuoka Children's Hospital for helpful discussion.

\section{Ethics}

Informed Consent: Written informed consent was obtained from the patient and his parents for the publication of this report.

Peer-review: Externally and internally peer-reviewed.

\section{Authorship Contributions}

Surgical and Medical Practices: Yuri Sonoda, Kenichiro Yamamura, Kanako Ishii, Kazuhirro Ohkubo, Kenji Ihara, Concept: Yuri Sonoda, Kenichiro Yamamura, Kenji Ihara, Design: Yuri Sonoda, Kenichiro Yamamura, Yasunari Sakai, Data Collection or Processing: Yuri Sonoda, Kenichiro Yamamura, Analysis or Interpretation: Yuri Sonoda, Kanako Ishii, Kazuhiro Ohkubo, Kenji Ihara, Shouichi Ohga, Literature Search: Yuri Sonoda, Kenichiro Yamamura,
Yasunari Sakai, Writing: Yuri Sonoda, Kenichiro Yamamura, Kanako Ishii, Kazuhiro Ohkubo, Kenji Ihara, Yasunari Sakai, Shouichi Ohga.

Financial Disclosure: This work was supported by JSPS KAKENHI grant number: 18K15677 (Yuri Sonoda).

\section{References}

1. Li L, Jick S, Breitenstein S, Hernandez G, Michel A, Vizcaya D. Pulmonary arterial hypertension in the USA: an epidemiological study in a large insured pediatric population. Pulm Circ 2017;7:126-136.

2. Frumkin LR. The pharmacological treatment of pulmonary arterial hypertension. Pharmacol Rev 2012;64:583-620. Epub 2012 Jun 1

3. Chadha C, Pritzker M, Mariash CN. Effect of epoprostenol on the thyroid gland: enlargement and secretion of thyroid hormone. Endocr Pract 2009; 15:116-121.

4. Satoh M, Aso K, Nakayama T, Naoi K, Ikehara S, Uchino Y, Shimada H, Takatsuki S, Matsuura H, Saji T. Autoimmune thyroid disease in children and adolescents with idiopathic pulmonary arterial hypertension. Circ J 2010;74:371-374. Epub 2009 Dec 15

5. Trapp CM, Elder RW, Gerken AT, Sopher AB, Lerner S, Aranoff GS, Rosenzweig EB. Pediatric pulmonary arterial hypertension and hyperthyroidism: a potentially fatal combination. J Clin Endocrinol Metab 2012;97:2217-2222. Epub 2012 May 23

6. Satoh M, Aso K, Nakayama T, Saji T. Effect of treatment with epoprostenol and endothelin receptor antagonists on the development of thyrotoxicosis in patients with pulmonary arterial hypertension. Endocr J 2017;64:1173-1180. Epub 2017 Sep 9

7. Zhou W, Dowell DR, Huckabee MM, Newcomb DC, Boswell MG, Goleniewska K, Lotz MT, Toki S, Yin H, Yao S, Natarajan C, Wu P, Sriram S, Breyer RM, Fitzgerald GA, Peebles RS Jr. Prostaglandin I2 signaling drives Th1 7 differentiation and exacerbates experimental autoimmune encephalomyelitis. PLoS One 2012;7:e33518. Epub 2012 May 10

8. Li H, Bradbury JA, Dackor RT, Edin ML, Graves JP, DeGraff LM, Wang PM, Bortner CD, Maruoka S, Lih FB, Cook DN, Tomer KB, Jetten AM, Zeldin DC. Cyclooxygenase-2 regulates Th1 7 cell differentiation during allergic lung inflammation. Am J Respir Crit Care Med 2011;184:37-49. Epub 2011 Apr 7

9. Zhou W, Zhang J, Goleniewska K, Dulek DE, Toki S, Newcomb DC, Cephus JY, Collins RD, Wu P, Boothby MR, Peebles RS, Jr. Prostaglandin I2 Suppresses Proinflammatory Chemokine Expression, CD4 T Cell Activation, and STAT6-Independent Allergic Lung Inflammation. J Immunol 2016;197:1577-1586. Epub 2016 Jul 25

10. Tsai MK, Hsieh CC, Kuo HF, Lee MS, Huang MY, Kuo CH, Hung CH. Effect of prostaglandin $\mathrm{I} 2$ analogs on monocyte chemoattractant protein-1 in human monocyte and macrophage. Clin Exp Med 2015;15:245-253. Epub 2014 Aug 26

11. Florentin J, Coppin E, Vasamsetti SB, Zhao J, Tai YY, Tang Y, Zhang Y, Watson A, Sembrat J, Rojas M, Vargas SO, Chan SY, Dutta P. Inflammatory Macrophage Expansion in Pulmonary Hypertension Depends upon Mobilization of Blood-Borne Monocytes. J Immunol 2018;200:3612-3625. Epub 2018 Apr 9

12. Sobota RM, Müller PJ, Heinrich PC, Schaper F. Prostaglandin E1 inhibits IL-6-induced MCP-1 expression by interfering specifically in IL-6dependent ERK1/2, but not STAT3, activation. Biochem J 2008;412:6572 .

13. Bogaard HJ, Al Husseini A, Farkas L, Farkas D, Gomez-Arroyo J, Abbate A, Voelkel NF. Severe pulmonary hypertension: The role of metabolic and endocrine disorders. Pulm Circ 2012;2:148-154. 